\title{
Deformation mechanisms of Mo alloyed FeCoCrNi high entropy alloy: In situ neutron diffraction
}

DOI:

10.1016/j.actamat.2017.01.034

Document Version

Accepted author manuscript

Link to publication record in Manchester Research Explorer

\section{Citation for published version (APA):}

Cai, B., Liu, B., Kabrada, S., Wang, Y., Yan, K., Lee, P., \& Liu, Y. (2017). Deformation mechanisms of Mo alloyed FeCoCrNi high entropy alloy: In situ neutron diffraction. Acta Materialia.

https://doi.org/10.1016/j.actamat.2017.01.034

\section{Published in:}

Acta Materialia

\section{Citing this paper}

Please note that where the full-text provided on Manchester Research Explorer is the Author Accepted Manuscript or Proof version this may differ from the final Published version. If citing, it is advised that you check and use the publisher's definitive version.

\section{General rights}

Copyright and moral rights for the publications made accessible in the Research Explorer are retained by the authors and/or other copyright owners and it is a condition of accessing publications that users recognise and abide by the legal requirements associated with these rights.

\section{Takedown policy}

If you believe that this document breaches copyright please refer to the University of Manchester's Takedown Procedures [http://man.ac.uk/04Y6Bo] or contact uml.scholarlycommunications@manchester.ac.uk providing relevant details, so we can investigate your claim.

\section{OPEN ACCESS}


3 Biao Cai ${ }^{1,2}$, Bin Liu ${ }^{3}$, Saurabh Kabra ${ }^{4}$, Yiqiang Wang ${ }^{1,2}$, Kun Yan $^{1,2}$, Peter Lee ${ }^{1,2^{* *}}$, Yong Liu ${ }^{3 *}$

$4 \quad{ }^{1}$ School of Materials, University of Manchester, M13 9PL, UK

$5{ }^{2}$ Research Complex at Harwell, Rutherford Appleton Laboratory, Harwell, Oxfordshire, OX11 0FA, 6 UK

$7 \quad{ }^{3}$ State Key Laboratory for Powder Metallurgy, Central South University, 410008, China

$8 \quad{ }^{4}$ ISIS Facility, Rutherford Appleton Laboratory, Didcot, Oxfordshire, OX11 0QX, UK

9 Abstract

A FeCoCrNiMo 2.3 high entropy alloy was processed by powder metallurgy with two conditions: hot extruded and annealed. In situ neutron Diffraction, together with electron microscopy, was used to study the deformation mechanisms and concomitant microstructural evolution for both conditions. The as-extruded alloy has a single face-centered-cubic structure with a calculated stacking fault energy of $\sim 19 \mathrm{~mJ} / \mathrm{m}^{2}$. When the alloy is tensile deformed, nano-twins and microbands are induced, resulting in an excellent combination of strength and ductility. Annealing at $800{ }^{\circ} \mathrm{C}$ for $72 \mathrm{~h}$ led to an increase of the strength of the alloy, but a decrease of the ductility. This is due to the decomposition of the alloy after annealing, causing the formation of Mo-rich intermetallic particles and a decrease of the stacking fault probability. These results highlight that combined mechanisms (i.e. solute strengthening and twin/microband induced plasticity) can effectively improve both the strength and ductility of high entropy alloys.

\section{Introduction}

The compelling need for high strength and ductile engineering alloys is driving the development of new concepts in alloy design. One intriguing new strategy is high-entropy alloys (HEA), which aims to maximize the configuration entropy and to form a single phase microstructure through combining multiple elements in an equimolar or near equimolar ratio 
28 [1]. One typical HEA system is based on five transition elements ( $\mathrm{Ni}, \mathrm{Cr}, \mathrm{Mn}, \mathrm{Fe}$ and $\mathrm{Co}$ ), denoted here as tHEA, e.g. FeCoCrNiMn [1]. This system has been developed extensively with a number of variants in compositions, showing great potential for creating exceptional engineering alloys [2-9].

Although many of tHEA variants form multi-phase microstructures with superior properties [6,10-12], single phase FeNiCrMnCo based tHEAs are still desirable in order to make use of high entropy effects, and to illustrate fundamental mechanical aspects of HEAs. Single phase tHEA can be obtained by thermo-mechanical processing of cast alloys [10] or powder metallurgy (PM) approaches $[4,13,14]$. Here, we have produced a face-centered cubic (FCC) single phase $\mathrm{FeCoCrNiMo}_{0.23}$ alloy (tHEA-Mo) through a powder metallurgy route. This powder metallurgy process includes (i) fabrication of pre-alloyed tHEA-Mo powder via gas atomization, and (ii) hot extrusion of the canned powders, as detailed in Ref. [14]. The newly-developed $\mathrm{FeNiCrCoMo}{ }_{0.23}$ alloy displays an excellent strength-ductility combination (see Table 1) with an ultimate tensile strength of $784 \mathrm{MPa}$ and elongation over $50 \%$. A good combination of strength and ductility has been found in various tHEA variants, which is attributed to twinning induced plasticity (TWIP) $[2,7,10,15]$, phase transformation induced plasticity [16] and/or micro-band formation [17]. Interestingly, all three mechanisms have also been identified in austenite steels with a low to medium stacking fault energy [18-20]. By analogy with its counterparts and austenite steels, we suspect that similar mechanisms may play an important role in the outstanding strength and ductility of the present tHEA-Mo alloy, which we aim to confirm in this study.

Transmission electron microscopy (TEM) has generally been used to study the microstructural response to the applied deformation in a wide variety of tHEAs, revealing the dislocation structure formation [17], stacking faults [21], deformation twins [2], and microbands [17]. However, only a small region is characterized by TEM, which may not 
53 provide representative information of the bulk. Neutrons can penetrate deeply into most

54 metallic alloys, allowing neutron diffraction to probe the average microstructural response of 55 the bulk material, including lattice strain evolution [22,23], mechanical twinning and stress56 induced phase transformation [22,24]. It has also been used in tHEAs at both room 57 temperature [25,26] and high temperatures [25]. Here, we have performed in situ time-of58 flight neutron diffraction studies on $\mathrm{PM} \mathrm{FeNiCrCoMo}{ }_{0.23}$ tHEA alloy during uniaxial tensile loading in conjunction with post-mortem microstructure analysis. Two specimens at asextruded and as-annealed conditions were tested. The evolution of micro-scale lattice strain and stacking fault probability as a function of deformation was quantified. This study attempts, on one hand, to elucidate the microstructure-mechanical behaviour relationship of FeNiCrCoMo 2.3 alloy, and on the other hand to facilitate our understanding of the deformation mechanisms activated in high entropy alloys.

\section{Materials and Methods}

The melt was prepared using a mixture of high purity (99.99\%) Fe, Co, Cr, Ni and Mo in an induction vacuum furnace. The melt was then dropped through a ceramic tube, and atomized by high purity Ar with $4 \mathrm{MPa}$ atomization pressure, forming droplets which rapidly solidified into powder particles. The as-prepared powder (average diameter $50 \mu \mathrm{m}$ ) was encapsulated into a can made of stainless steel with an inner diameter of $60 \mathrm{~mm}$ and a length of $150 \mathrm{~mm}$. The encapsulated powder was pre-heated to $1200{ }^{\circ} \mathrm{C}$ for $1 \mathrm{~h}$, and immediately subjected to hot extrusion at $1200{ }^{\circ} \mathrm{C}$ with an extrusion ratio of $9.5: 1$ and a velocity of $\sim 10$ $\mathrm{mm} / \mathrm{s}$ on a $2500 \mathrm{~T}$ hydraulic press. After hot extrusion, the bars were air cooled. The resulting bar composition was $\mathrm{Fe}_{23.2} \mathrm{Co}_{23.9} \mathrm{Ni}_{23.8} \mathrm{Cr}_{23.7} \mathrm{Mo}_{2.3}$ (at.\%). The grain structure of the asextruded alloy is shown in Fig. 1a. The grain size is around $35 \mu \mathrm{m}$, and a few twins can be observed. Part of the as-extruded samples were subjected to annealing treatment at $800{ }^{\circ} \mathrm{C}$

77 for 72 h. After annealing, dense intermetallic particles enriched with Mo 
$78\left(\mathrm{Mo}_{25.2} \mathrm{Co}_{20.6} \mathrm{Cr}_{25.4} \mathrm{Fe}_{17.8} \mathrm{Ni}_{11.1}\right.$ in wt.\%, as compared to the matrix: $\mathrm{Mo}_{8.2} \mathrm{Co}_{24.2} \mathrm{Cr}_{21.5} \mathrm{Fe}_{22.4} \mathrm{Ni}_{23.7}$,

79 measured by EDS in SEM) were formed both along grain boundaries and in the grain interior 80 (Fig. 1b).

81 In situ time-of flight (TOF) neutron diffraction measurements during tensile deformation 82 were performed on the ENGIN-X diffractometer using a stress rig (ISIS spallation neutron source, the Rutherford Appleton Laboratory, UK)[27]. Fig. 2 shows the schematic of the in situ tensile loading setup. The stress rig has a load capability of $\pm 100 \mathrm{kN}$ mounted on the diffractometer horizontally. Dog-bone tensile samples (dimensions shown in Fig. 2) were used from both the as-extruded and as-annealed bars. The loading axis is parallel to the extruded direction and oriented $45^{\circ}$ relative to the incident beam. The two $\pm 90^{\circ}$ detector banks (i.e., axial and radial detectors) allow simultaneous collection of diffraction patterns parallel and perpendicular to the loading direction of the specimen. The patterns recorded in the axial detector contain refractions from grain families for which the plane normals are parallel to the applied load. The neutron scattering gauge volume was $4 \times 4 \times 4 \mathrm{~mm}^{3}$, which was defined by the $4 \times 4 \mathrm{~mm}^{2}$ incident slit, and the $4 \mathrm{~mm}$ wide receiving collimators. Diffraction patterns were acquired for $20 \mathrm{~min}$ intervals between tensile loading steps, iterating until the sample failed. A stress control mode was used until yielding, followed by displacement-control.

97 package [28], allowing the determination of interplanar lattice spacing (d), diffraction 98 intensity $(I)$ and full width at half maximum (FWHM). Lattice strain was calculated using:

$$
\varepsilon_{h k l}^{\exp }=\frac{d_{h k l}-d_{h k l}^{0}}{d_{h k l}^{0}}
$$

99 where $d_{h k l}$ is the interplanar lattice spacing of $(h k l)$ plane at different load steps whereas $d_{h k l}^{0}$ 100 is the interplanar spacing at the start of deformation. 
were performed to examine the microstructure of the samples. a field emission scanning electron microscope (FESEM) (FEI Nova Nano230, USA) coupled with electron backscattered diffraction (EBSD) was used. The acceleration voltage during the EBSD measurements was $30 \mathrm{kV}$, the beam current was approximately $100 \mathrm{~mA}$, and the step size is 1um. Electron Probe Micro Analysis (EPMA) was carried out by a JEOL-JA-8230 SEM equipped with a wavelength dispersive spectrometern at $15 \mathrm{kV}$ and dwell time of $40 \mathrm{~ms}$. FEI Quanta 650 SEM was used to characterize the fracture morphology and intermetallic particles. TEM samples were extracted from the necked region of the failed specimens after tensile deformation. They were ground down to $\sim 100 \mu \mathrm{m}$ foil, then disks of $3 \mathrm{~mm}$ diameter were punched out. Ion milling (Fischione Model 1050) at $6 \mathrm{kV}$ with a final angle of $1^{\circ}$ was used to

112 produce electron transparent regions in the central part of the disks. TEM investigations were conducted in a JEOL-2100 microscopy operated at $200 \mathrm{kV}$. Techniques including bright field (BF) imaging, diffraction, dark field scanning-TEM imaging (DF-STEM) and energy dispersive X-ray spectroscopy (EDS) were used.

\section{Results and Discussion}

\subsection{Mechanical properties}

Fig. 3a shows the macroscopic engineering stress/strain (blue line) behaviour of the asextruded PM tHEA-Mo alloy together with its true stress-true strain curve (pink line). The points at which neutron diffraction patterns were taken are clearly visible due to the load relaxation that occured during the 20 min holding period. The alloy exhibits an excellent

122 combination of high strength and ductility, with a yield stress (YS) of $328 \mathrm{MPa}$, an ultimate 123 tensile strength (UTS) of $784 \mathrm{MPa}$, together with $53 \%$ total elongation. The Young's modulus $E$ of the alloy is $287 \mathrm{GPa}$. A very high work hardening rate can be observed from the true stress-strain curve. 
127 tHEA-Mo after annealing at $800{ }^{\circ} \mathrm{C}$ for $72 \mathrm{~h}$ increases to $942 \mathrm{MPa}$, but the yield stress slight 128 decreases to $352 \mathrm{MPa}$, and the elongation lowers to $18 \%$. Its Young's Modulus is about 274

129 GPa. The increase of strength might be due to the formation of hard intermetallic particles 130 during heat treatment (Fig. 1b) [29].

131 Ludwik's equation [30] is used to fit the measured true stress-strain curves. Equ. 2 and 3

132 are the resulting equations for the as-extruded and as annealed alloys, respectively. The work

133 hardening exponent $(n)$ of the HEA-Mo alloy at the extruded and annealed conditions are

1340.83 and 0.51 , respectively. The exponent value of the as-extruded tHEA-Mo alloy is very 135 close to the measurement by Liu et al on an as-cast FeCoCrNi alloy (e.g. 0.75) [29].

136 Annealed tHEA-Mo has a lower hardening exponent compared with the as-extruded alloy.

137 Higher exponent value is often related to enhanced uniform elongation and more 138 homogeneous deformation, resulting in superior formability [29,31].

$$
\begin{aligned}
& \sigma=378+40 \varepsilon^{0.83} \\
& \sigma=350+149 \varepsilon^{0.51}
\end{aligned}
$$

139 The mechanical properties of tHEA-Mo alloy processed by both routes are listed in

140 Table 1, together with a few other HEA alloys. A few points can be drawn.

141 Firstly, PM processed tHEA alloys (both FeCoCrNi and $\mathrm{FeCoCrNiMo}{ }_{0.23}$ ) have higher

142 YS and UTS than those alloys fabricated by casting and thermo-mechanical processing with

143 similar compositions. Casting of HEA alloys tends to form segregation during solidification.

144 Although subsequently thermo-mechanical processes can reduce the segregation, it may still

145 lead to heterogeneity in both the composition and microstructures of the final alloy, hence

146 deteriorating the mechanical performance. The PM approach in this study used fine powders

147 made by gas atomization, minimizing segregation and alleviating the undesirable effects. 

compared to PM FeCoCrNi alloy. The alloying of Mo might cause local distortion in the FCC structure [29], inducing the solution strengthening effect. This demonstrates that micro-

151 alloying could be used to further strengthen single phase HEAs, opening a potentially new 152 prospective for HEA alloy design. Thirdly, exceptional elongation (around 50\%) with good strength has been achieved in most of the FeNiCoCrMn based HEAs with single FCC structure (see Table 1).

Table 1 Yield strength (YS), ultimate tensile strength (UTS) and elongation of tHEAs at room temperature in the present study and selected prior studies. Values in brackets are from in situ neutron tensile tests.

\begin{tabular}{ccccc}
\hline Materials & Processing methods & YS (MPa) & UTS (MPa) & Elongation (\%) \\
\hline FeCoCrNiMo $_{0.23}$ & PM-extruded & $378(369)$ & $784(829)$ & $53(51)$ \\
FeCoCrNiMo $_{0.23}$ & PM-annealed & $(350)$ & $(942)$ & $(18)$ \\
FeCoCrNi [14] & PM-extruded & 359 & 712.5 & 56 \\
FeCoCrNiMo $_{0.2}[29]$ & As-cast & 254.7 & 589.6 & 55.1 \\
FeNiCoCrMn [32] $_{\text {FeCoCrNi [29] }}$ & Cast+cold rolled & 165 & 520 & 65 \\
FeCoCrMnFeNi[2] & As-cast & 155 & 472.4 & 58.9 \\
& swage+Anneal & 265 & 600 & 45
\end{tabular}

157

\subsection{Neutron diffraction}

Fig. $4 \mathrm{a}$ and $4 \mathrm{~b}$ show the neutron spectra of the as-extruded $\mathrm{FeCoCrNiMo}_{0.23}$ alloy

160 recorded on the axial and radial detectors, respectively. Three different stress levels $(0,418$ and $755 \mathrm{MPa}$ ) are shown. General observations are listed below, followed by detailed quantification: single phase structure. No new peaks appear during deformation. 
- The diffraction peak positions change at different stress levels. As stress increases, the peaks in Fig. 4a (axial detector) shift to higher d-spacing, while those in Fig. 4b (radial detector) shift to lower d-spacing. This is due to the Poisson's ratio contraction.

- As applied stress increases, the intensity of diffraction peaks varies significantly. For

trend. With the help of the Rietveld refinement method, the lattice parameter $a_{0}$ of both alloys

are derived as listed in Table 2. Annealing slightly decreases the lattice parameter.

Fig. $5 \mathrm{a}$ and $5 \mathrm{~b}$ shows the evolution of measured axial lattice strains $\varepsilon_{h k l}^{\exp }$ parallel to the loading direction for different grain families up to a stress level close to the failure of the asextruded and as-annealed tHEA-Mo alloy, respectively. Note that there are two possible sources that can contribute to peak shifts: (1) $(h k l)$ dependent macro-strain referring to $\varepsilon_{h k l}^{\text {strain }}$, and (2) stacking faults referring to $\varepsilon_{h k l}^{s f}$. The stacking fault and $(h k l)$ dependent macro-strains can be correlated with the experimentally measured lattice strain via $[33,34]$ :

$\varepsilon_{h k l}^{\text {exp }}=\varepsilon_{h k l}^{\text {strain }}-\varepsilon_{h k l}^{s f}=\varepsilon_{h k l}^{\text {strain }}-\frac{\sqrt{3}}{4 \pi} \frac{\sum_{b} \pm(h+k+l)}{(u+b)\left(h^{2}+k^{2}+l^{2}\right)} S F P$

where $u$ and $b$ are the numbers of non-broadened and broadened components due to stacking 184 faults, respectively, and SFP is the stacking fault probability.

In alloys where the stacking fault energy (SFE) is low, a significant amount of stacking fault can be introduced when the sample is strained, which will contribute to the 187 peak shifts. This has been shown to occur in austenitic steels with low SFE [33]. Single phase 
FCC tHEAs is considered to be similar to austenitic steels, hence the change of the inter-

189 planner spacing $\left(\varepsilon_{h k l}^{e x p}\right)$ might be a result of both the occurrence of stacking fault and $(h k l)$ -

190 plane dependent macro-strain. Here we first discuss the evolution of $\varepsilon_{h k l}^{e x p}$ upon deformation,

191 then we adopt the method used by Jeong et al. [33,34] to measure the stacking fault

192 probability (SFP).

193 Two deformation stages with varying slopes are visible in Fig. 5a: (I) linear elastic

194 loading and (II) a linear plastic stage after a short transition from elastic to plastic 195 deformation. In stage I (elastic regime), before the yield point, all the lattice strains respond proportionately to the applied stress. We have calculated the elastic modulus of various grain orientations, shown in Table 2. The (200) grains exhibit the lowest elastic modulus, followed by (311), (111), and then (110), consistent with the cubic elastic anisotropy factor [35]. After stage I, a clear transition point/short period can be found where the stress-lattice strain relationship becomes nonlinear, indicating the onset of yielding as loads are redistributed. In this period, the load transfers from 'softer' grain families, e.g. (220), to 'harder' grain families, e.g. (200). Afterwards, stage II is reached, during which the lattice strains respond linearly to the applied stress again. In this stage almost all grain families except (200) show the same slope as that in the elastic regime. The fact that the slope of (200) grain drops from stage I to stage II indicates that (200) orientated grains have a higher directional strength-tostiffness ratio among those orientations [36], hence accommodating more load when the sample is further tensile plastically strained.

Fig. $5 \mathrm{~b}$ shows the development trend of lattice strain in the annealed tHEA-Mo sample.

209 Similar to that of the as-extruded one (Fig. 5a), two distinctive stages can be observed. The 210 slope of (200) grain family in the annealed sample becomes smaller than that in the asextruded sample in the transition period, which suggests the (200) grain family becomes 'harder' after annealing. 
214 conditions. The annealed alloy has a higher elastic modulus in all grain families than the as-

215 extruded sample. The Young's Modulus anisotropy $\left(=E_{111} / E_{200}\right)$ is about 1.95 and 1.86 for the

216 two alloys, which is consistent with the work of $\mathrm{Wu}$ et al.[26], (i.e. 1.98 for

$217 \mathrm{Fe}_{20} \mathrm{Co}_{20} \mathrm{Ni}_{20} \mathrm{Cr}_{20} \mathrm{Mn}_{20}$, at.\%).

218 Table 2. Lattice parameter, elastic modulus (for different grain orientations) and stacking fault energy of tHEA-Mo alloys in as-extruded and annealed conditions.

\begin{tabular}{cccccccc}
\hline & $\mathrm{a}_{0}$ & $\mathrm{E}_{200}$ & $\mathrm{E}_{311}$ & $\mathrm{E}_{111}$ & $\mathrm{E}_{220}$ & Modulus & SFE \\
HEA-Mo & $(\mathrm{nm})$ & $(\mathrm{GPa})$ & $(\mathrm{GPa})$ & $(\mathrm{GPa})$ & $(\mathrm{GPa})$ & anisotropy & $\left(\mathrm{mJ} / \mathrm{m}^{2}\right)$ \\
\hline As-extruded & 0.3604 & 145 & 207 & 283 & 299 & 1.95 & 19 \\
Annealed & 0.3575 & 166 & 233 & 308 & 311 & 1.86 & $\sim$ \\
\hline
\end{tabular}

220

Fig. 5c plots the (111) and (222) lattice strain as a function of true strain of the asextruded tHEA-Mo alloy. Increasing differences between the two were observed when true strain exceeded $10 \%$. When considering only peak shifts induced by (hkl)-plane dependent macro-strain, the measured lattice strain of the (111) and (222) planes should be exactly the same since they are equivalent crystallographic orientations [33]. However, the occurrence of stacking faults can lead to differences in lattice strain in the (111) and (222) reflections $[33,36]$.

Using equation (2), the stacking fault probability (SFP) was determined (Fig. 5c). It is noticeable that under $10 \%$ true strain, the SFP fluctuates with values less than 0 . After $10 \%$ true strains, the SFP becomes positive, and continuously increases with applied strain in an 231 almost linear manner, reaching to about $21 \times 10^{-3}$ at the end of deformation. This clearly 232 demonstrates the increasing fraction of stacking faults as deformation proceeds in the asextruded alloy. In addition, it seems that a critical amount of strain (about $10 \%$ true strain and 
$645 \mathrm{MPa}$ true stress) is needed to promote stacking fault formation in the as-extruded tHEA-

235 Mo alloy. For the annealed sample (Fig. 5d), the SFP varies with negative values below 7.6\%

236 true strain, and increases to only about $2.5 \times 10^{-3}$ before fracture, which is half of the value of

237 the as-extruded sample at a similar strain level, and one magnitude lower than that of the as

238 extruded alloy before facture. This indicates that the amount of stacking faults formed in the

239 annealed sample is insignificant. The particles formed during annealing will strongly

240 influence the evolution of dislocations in the matrix during deformation hence the formation

241 capacity of stacking faults. Specifically, the intermetallic particles can block the motion of

242 dislocations (strengthen the alloy) and prevent the formation of stacking faults in the matrix

243 which means a reduction of stacking fault probability. In both cases, at lower strain levels,

244 the stacking fault probability stays negative, which indicates that the effect of stacking faults on peak shift is not distinct at low strains [36].

Stacking fault energy (SFE, $\gamma_{S F}$ ) represents the ease of dissociation of a perfect dislocation into two partial dislocations and the propensity for the formation of SFs. It can be evaluated by Reed and Schramm's equation [37]:

$\gamma_{S F}=\frac{6.6 a_{0}}{\pi \sqrt{3}}\left(\frac{2 c_{44}}{c_{11}-c_{12}}\right)^{-0.37} \frac{\left\langle\varepsilon_{50}^{2}\right\rangle_{111}}{S F P}\left(\frac{c_{44}+c_{11}-c_{12}}{3}\right)$

249 where $a_{0}$ is the lattice parameter, $\left\langle\varepsilon_{50}^{2}\right\rangle_{111}$ is the mean square strain, $c_{11}, c_{12}$, and $c_{44}$ are the 250 single crystal elastic constants.

251 Eqn. 3 shows that the stacking fault energy is inversely proportional to the stacking fault probability. The single crystal elastic constants $c_{11}=216 \mathrm{GPa}, c_{12}=175 \mathrm{GPa}$, and $c_{44}=189 \mathrm{GPa}$ used in this study are from ab initio atomistic simulation on an $\mathrm{FCC} \mathrm{Fe}_{25} \mathrm{Co}_{25} \mathrm{Ni}_{25} \mathrm{Gr}_{25}$ alloy

254 [38]. $\left\langle\varepsilon_{50}^{2}\right\rangle_{111}$ was estimated by an integral breadth method with a pseudo-Voigt convolution 255 [39]. We then estimated the SFE of the as-extruded and annealed tHEA-Mo alloys at room temperature to be $19 \mathrm{~mJ} / \mathrm{m}^{2}$. The SFE of the as-extruded tHEA-Mo alloy correlates well with 
257 the range determined by Zaddach et al., e.g. $17.4-31.7 \mathrm{~mJ} / \mathrm{m}^{2}$ in an $\mathrm{FCC} \mathrm{Fe}_{25} \mathrm{Co}_{25} \mathrm{Ni}_{25} \mathrm{Gr}_{25}$ 258 alloy [40].

In prior studies Eqn. 5 has primarily been used to measure the SFE of pure metals [37] 260 or single phase alloys [33]. It has not been widely applied to multi-phase materials, although 261 recently it was used to calculate the SFE of the austenite phase in a duplex steel [41].

262 Although it may only be indicative, here we apply Eqn. 5 to the annealed multiphase tHEAMo sample, (which contains intermetallic precipitates, see Fig. 1b) to determine an estimate of the SFE, obtaining $\sim 135 \mathrm{~mJ} / \mathrm{m}^{2}$. Although more indicative of an upper bound (especially as the stacking fault probability is very low adding error to the calculation), the result suggests that the stacking fault energy of the annealed alloy is high enough that the formation of deformation twins is unfavourable.

The overlapping SF and partial dislocation bounding them can be considered as twinning constituents or twinning embryos [42]. In other words, the increasing width of SFs favours the formation of mechanical twinning. A critical stress is required for a mechanical twin to form [43]. This stress in the uniaxial form $\left(\sigma_{T}\right)$ can be described by [43]:

$\sigma_{T}=\frac{2}{m \times b_{p}} \gamma_{S F}$

272 where $m$ is the Schmid factor ( $m=0.471$ for loading along $\{220\}$ orientation[43]), $b_{p}$ is the 273 burger vector of a Shockley partial dislocation. With $\gamma_{S F}=19 \mathrm{~mJ} / \mathrm{m}^{2}$, the critical stress for 274 twinning to occur in the as-extruded tHEA-Mo alloy is $\sim 805 \mathrm{MPa}$ (corresponding to the true 275 strain of about12). Laplanche et al. [2] found that nano-twins in FeNiCoCrMn tHEA started 276 to form after the tensile stress reached $720 \pm 30 \mathrm{MPa}$ at about $25 \%$ true strain at room 277 temperature. The slight difference in the value of the critical stress might lie in the difference 278 in alloy composition and strain rate applied. However, note that as deformation proceeds, local stress concentration may exceed the critical stress for twining and might induce 
twinning those grains which are unfavourably in the as-extruded alloy. Also this stress

281

282

283

284 concentration effect might induce deformation twinning in the annealed alloy.

Fig. 5e shows the intensity changes of several peaks on the axial detector as a function of applied true stress of the as-extruded sample. Before macroscopic yielding, the peak intensity remains almost constant. After macroscopic yielding, significant changes in intensity are observed. The intensity of (111) grain family rises by a factor of about 11, and (200) grain family also increases by a factor of 4 . The (311) grain family increases slightly, then it lowers and broadens. On the other hand, the (220) peak intensity drops to zero when the true stress reaches $900 \mathrm{MPa}$. Fig. $5 \mathrm{f}$ shows the peak intensity on the axial detector as a function of applied true stress of the annealed sample. The trend is very similar to the asextruded sample, although the magnitude of intensity change of the annealed sample is much smaller (e.g. 4 times increase of (111) peak and 2 times increase of (200) peak). Interestingly, the (220) peak disappears when the sample is strained close to failure in both samples.

The change of peak intensity is attributed to the re-orientation of grains during the tensile deformation, which could be due to slip/rotation of grains and/or formation of mechanical twins. Grain slip/rotation has been well documented in the literature to account for peak intensity changes [25]. Deformation twinning can also cause a change in peak intensity. Firstly, when grains which are initially oriented to satisfy the diffraction condition, were twinning, the twinned portion can leave the diffraction condition. This reduces the diffraction intensity. Secondly, grains oriented such that when they twin, the twinned portion meets the diffraction condition, which can increase the diffraction intensity [44]. This concept has been used extensively in HCP structured alloys, especially Mg alloys [45], because the dominant twinning mode ( $\{10 \overline{1} 2\}$ twinning) in $\mathrm{Mg}$ can result in a nearly $90^{\circ}$ change in crystal orientation, which can cause a significant change in texture and hence peak intensity. However, there are rather limited applications of this concept in FCC structures as 
it becomes difficult to qualitatively separate the contributions of twinning and grain rotation

to the measured peak intensity change. In our case, we would not expect such a significant

307 change of peak intensity (e.g. 11 times increase of (111) peak intensity) by grain rotation 308 alone. Therefore, it is suggested that both rotation and twinning lead to re-orientation of

309 grains, which accounts for the significant intensity increase in the as-extruded tHEA-Mo

310 alloy. If we assume that the annealed tHEA-Mo alloy is unlikely to form twins during room temperature deformation due to its high stacking fault energy, its intensity change can only be a result of grain rotation, which is consistent to the fact that the intensity change of the annealed sample is much smaller than that of the as-extruded sample. However, further work is needed to distinguish the contribution of slip and twinning to the overall intensity change.

\subsection{Ex situ microscopic analysis}

In addition to the in situ diffraction quantification, we performed correlated TEM and images taken from the fractured specimen of the as-extruded tHEA-Mo alloy. Lamellar nano twins (Fig. 6a, recorded from [110] zone), confirmed by the inset selected-area diffraction patterns (SADP, Fig. 6b), are clearly visible. High densities of dislocation structures are trapped within and intersecting with the twin bundles. Two intermetallic particles (red arrows) can also be found. It seems the twins are curved, in particularly around the particle (the longer red arrow). Fig.6c shows intersections of twins, forming rhombic blocks. Fig. 6d

324 shows the formation of plate-like microbands in another grain. These TEM images confirm

325 that both twins and microbands have formed during room temperature tensile deformation to accommodate strain. plane [46]. The resulting nano-sized twins can act as strong obstacles to dislocation glide, attributing to the high strain hardening of the as-extruded alloy. The microbands (nano-sized 
banded structure with a small difference in grain orientation) form when perfect dislocations

331 become hard to move at a higher strain, hence they move into localized bands [21]. Microbands can also inhibit dislocation motion and strengthen the alloy, which was

333 illustrated in high Mn steels [47]. These results show that both twin induced plasticity and

334 microband induced plasticity can be active in this FCC single phase tHEA. This is consistent

335 with the work of Zhang et al. [21], which found that stacking faults, microbands and twins

336 were formed simultaneously in a FeCoNiCrMn HEA alloy that was in situ loaded under

337 tension in a TEM. Normally, deformation twinning occurs in alloys with a low SFE $[48,49]$

338 while microbands are formed in alloys with a medium to high SFE [47,50,51]. Although this

339 is the dominate mechanism, in addition to the aforementioned work of Zhang et al. [21], the

340 simultaneous observation of twinning and microband has been reported in several other

341 materials including austenite Fe-Mn-Al-C steels [19,52] and austenite-ferrite Fe-Mn-Al-C

342 steel [50]. This has been attributed to the role of grain orientation on both deformation

343 twinning and microband formation [19,53]; i.e. a grain will form deformation twins or

344 microbands depending on its orientation relative to the loading direction. This is indicated by

345 that fact that the Schmid factors for slipping and twinning in FCC alloys for the same grain orientation are different [43]. For this tHEA alloy with SFE as low as $19 \mathrm{~mJ} / \mathrm{m}^{2}$, deformation

347 twinning is the primary mechanism; however, grains with an unfavourable orientation for

348 twinning may, alternatively, form microbands to accommodate the strain.

349 Fig. $7 \mathrm{a}$ and $7 \mathrm{~b}$ show the bright field TEM images of the annealed sample after failure.

350 Dense dislocation structures and microbands were observed. The microbands form in one 351 grain but are absent in its neighbour (Fig. 7b), indicating their dependence on grain

352 orientation. The formation of microbands The SADP shows that no twinning was found in

353 this region. We did not find obvious twins in the TEM sample; confirming the neutron

354 diffraction suggested hypothesis that the annealed tHEA-Mo sample is inhibited from 
forming deformation twins due to its low stacking fault probability and high stacking fault energy. Fig. 7c shows the dark field STEM image of the annealed sample. Quite a few intermetallic particles are found which are enriched in Mo and deficit in $\mathrm{Ni}$ and $\mathrm{Fe}$ (Fig. 7d). These submicron intermetallic particles inhibit the motion of dislocations, enhancing the strength after the annealing treatment.

Fig. $8 \mathrm{a}$ and $8 \mathrm{~b}$ shows the longitudinal cross-section of the fractured tHEA-Mo sample in the as-extruded and annealed condition, respectively. Elongated micro-cavities are found in both samples. In the extruded sample, the elongated cavities are shown to decorate along the grain boundaries. In the annealed sample, cavities can be seen to locate in conjunction with the particles, indicating that the stress are concentrated around the particles, and the interfacial bonding of the two is weak. In addition, the interface might be a 'sink' for vacancies, resulting in the formation of cavities around the particle/matrix interface and the early fracture of the sample.

Fig. $8 \mathrm{c}$ and $8 \mathrm{~d}$ show the fracture surface of the as-extruded and annealed specimen, respectively. Ductile dimples can be found in both samples, and it seems that the as-extruded sample has slightly finer dimples than the annealed one. Intermetallic particles are present inside the dimples in both samples. Note submicron intermetallic particles can be occasionally observed by TEM in the as-extruded alloy, as shown in Fig.8c inset, although we do not observe intermetallic particles by SEM (Fig. 8a).

\section{Conclusions}

A single phase FCC structured $\mathrm{FeCoCrNiMo}_{0.23}$ high entropy alloy (HEA) was prepared by a powder metallurgy route. The as-extruded alloy from HEA powder shows a superb combination of ductility (51\% elongation) and strength (830 MPa UTS). Annealing of the as-extruded alloy at $800{ }^{\circ} \mathrm{C}$ for $72 \mathrm{~h}$ increases the strength to $942 \mathrm{MPa}$ but sacrifices its elongation $(18 \%)$. In situ neutron diffraction was used to evaluate the evolution of lattice 
380

381

382

strain and stacking fault probability in both conditions, and correlated to electron microscopy. This correlative investigation revealed the microstructural changes due to tensile deformation, leading to the following conclusions:

1. Micro alloying of Mo was found to increase the strength of the FeCoCrNi based HEA alloy, demonstrating the potential of utilizing the solute solution strengthening effect in HEAs. The as-extruded alloy has a low stacking fault energy $\left(\sim 19 \mathrm{~mJ} / \mathrm{m}^{2}\right)$, which can induce the formation of stacking faults, deformation twinning and microbands, accounting for its high ductility and strength.

2. Annealing causes decomposition of the alloy, forming Mo-rich intermediate particles. The annealed alloy is strengthened by those intermetallic particles. However, its ductility decreases due to (1) the weak interfacial bonding between the particles and the matrix, and (2) the decrease of the stacking fault probability inhibiting the formation of deformation twins.

\section{Data statement}

A representative sample of research data from the experiments along with the plot data for the graphs in this manuscript is provided in supplementary material [ $\mathrm{xxx}$ ]. The underlying data is not provided online due to its very large size.

\section{Acknowledgement}

The authors thanks ISIS for providing the beamtime (RB1610297) and staff at EnginX beamline for support. B.C., Y.Q.W. and P.D.L. acknowledge the support provided by the Research Complex at Harwell, and funding from the UK-EPSRC (EP/K007734/1, EP/I02249X/1 and EP/L018705/1). Y.L. and B.L. acknowledge the National Natural Science Foundation of China (51671217), and together with B.C., the Projects of Innovation-driven Plan in Central South University of China (2015CX004). The authors are grateful to Drs. Cunnea and Gilchrist for assistance with the TEM analysis. 


\section{References}

406 [1] J.W. Yeh, S.K. Chen, S.J. Lin, J.Y. Gan, T.S. Chin, T.T. Shun, et al., Nanostructured high-entropy alloys with multiple principal elements: Novel alloy design concepts and outcomes, Adv. Eng. Mater. 6 (2004) 299-303+274. doi:10.1002/adem.200300567.

G. Laplanche, A. Kostka, O.M. Horst, G. Eggeler, E.P. George, Microstructure evolution and critical stress for twinning in the $\mathrm{CrMnFeCoNi}$ high-entropy alloy, Acta Mater. 118 (2016) 152-163. doi:10.1016/j.actamat.2016.07.038.

[3] Z. Tang, T. Yuan, C.-W. Tsai, J.-W. Yeh, C.D. Lundin, P.K. Liaw, Fatigue behavior of a wrought A10.5CoCrCuFeNi two-phase high-entropy alloy, Acta Mater. 99 (2015) 247-258. doi:10.1016/j.actamat.2015.07.004.

[4] Z. Fu, W. Chen, H. Wen, D. Zhang, Z. Chen, B. Zheng, et al., Microstructure and strengthening mechanisms in an FCC structured single-phase nanocrystalline Co25Ni25Fe25A17.5Cu17.5 high-entropy alloy, Acta Mater. 107 (2016) 59-71. doi:10.1016/j.actamat.2016.01.050.

[5] Y.F. Ye, Q. Wang, J. Lu, C.T. Liu, Y. Yang, High-entropy alloy: Challenges and prospects, Mater. Today. 19 (2015). doi:10.1016/j.mattod.2015.11.026.

[6] Z. Li, K.G. Pradeep, Y. Deng, D. Raabe, C.C. Tasan, Metastable high-entropy dualphase alloys overcome the strength-ductility trade-off, Nature. 534 (2016) 1-8. doi:10.1038/nature17981.

424 [7] Y. Deng, C.C. Tasan, K.G. Pradeep, H. Springer, A. Kostka, D. Raabe, Design of a twinning-induced plasticity high entropy alloy, Acta Mater. 94 (2015) 124-133. doi:10.1016/j.actamat.2015.04.014.

427 [8] B. Gludovatz, A. Hohenwarter, K.V.S. Thurston, H. Bei, Z. Wu, E.P. George, et al., Exceptional damage-tolerance of a medium-entropy alloy CrCoNi at cryogenic temperatures, Nat. Commun. 7 (2016) 10602. doi:10.1038/ncomms10602. 
[9] Y. Brif, M. Thomas, I. Todd, The use of high-entropy alloys in additive manufacturing, Scr. Mater. 99 (2015) 93-96. doi:10.1016/j.scriptamat.2014.11.037.

[10] F. Otto, A. Dlouhý, C. Somsen, H. Bei, G. Eggeler, E.P. George, The influences of temperature and microstructure on the tensile properties of a CoCrFeMnNi highentropy alloy, Acta Mater. 61 (2013) 5743-5755. doi:10.1016/j.actamat.2013.06.018.

[11] Y. Lu, Y. Dong, S. Guo, L. Jiang, H. Kang, T. Wang, et al., A promising new class of high-temperature alloys: eutectic high-entropy alloys., Sci. Rep. 4 (2014) 6200. doi:10.1038/srep06200.

[12] I.S. Wani, T. Bhattacharjee, S. Sheikh, P.P. Bhattacharjee, S. Guo, N. Tsuji, Tailoringnanostructures and mechanical properties of $\mathrm{AlCoCrFeNi2}$.1 eutectic high entropy alloy using thermo-mechanical processing, Mater. Sci. Eng. A. (2016). doi:10.1016/j.msea.2016.08.048.

[13] Y. Liu, J. Wang, Q. Fang, B. Liu, Y. Wu, S. Chen, Preparation of superfine-grained high entropy alloy by spark plasma sintering gas atomized powder, Intermetallics. 68 (2016) 16-22. doi:10.1016/j.intermet.2015.08.012.

[14] B. Liu, J. Wang, Y. Liu, Q. Fang, Y. Wu, S. Chen, et al., Microstructure and mechanical properties of equimolar FeCoCrNi high entropy alloy prepared via powder extrusion, Intermetallics. 75 (2016) 25-30. doi:10.1016/j.intermet.2016.05.006.

[15] A. Soulami, K.S. Choi, Y.F. Shen, W.N. Liu, X. Sun, M.A. Khaleel, On deformation twinning in a $17.5 \%$ Mn-TWIP steel: A physically based phenomenological model, Mater. Sci. Eng. A. 528 (2011) 1402-1408. doi:10.1016/j.msea.2010.10.031.

[16] E. Cakmak, H. Choo, K. An, Y. Ren, A synchrotron X-ray diffraction study on the phase transformation kinetics and texture evolution of a TRIP steel subjected to torsional loading, Acta Mater. 60 (2012) 6703-6713. doi:10.1016/j.actamat.2012.08.040. 
[17] Z. Wang, I. Baker, Z. Cai, S. Chen, J.D. Poplawsky, W. Guo, The effect of interstitial carbon on the mechanical properties and dislocation substructure evolution in Fe40.4Ni11.3Mn34.8A17.5Cr6 high entropy alloys, Acta Mater. Submitted (2016) 228-239. doi:10.1016/j.actamat.2016.08.072.

[18] I. Gutierrez-Urrutia, D. Raabe, Dislocation and twin substructure evolution during strain hardening of an Fe-22 wt.\% Mn-0.6 wt.\% C TWIP steel observed by electron channeling contrast imaging, Acta Mater. 59 (2011) 6449-6462. doi:10.1016/j.actamat.2011.07.009.

[19] I. Gutierrez-Urrutia, D. Raabe, Multistage strain hardening through dislocation substructure and twinning in a high strength and ductile weight-reduced Fe-Mn-Al-C steel, Acta Mater. 60 (2012) 5791-5802. doi:10.1016/j.actamat.2012.07.018.

[20] B.L. Ennis, E. Jimenez-Melero, E.H. Atzema, M. Krugla, M.A. Azeem, D. Rowley, et al., In situ study of austenite driven work-hardening behaviour in a TRIP-assisted dual phase steel, Int. J. Plast. (2016). doi:10.1016/j.ijplas.2016.10.005.

[21] Z.Z. Zhang, M.M. Mao, J. Wang, B. Gludovatz, Z.Z. Zhang, S.X. Mao, et al., Nanoscale origins of the damage tolerance of the high-entropy alloy CrMnFeCoNi., Nat. Commun. 6 (2015) 10143. doi:10.1038/ncomms10143.

[22] J.A. Wollmershauser, S. Kabra, S.R. Agnew, In situ neutron diffraction study of the plastic deformation mechanisms of $\mathrm{B} 2$ ordered intermetallic alloys: $\mathrm{NiAl}, \mathrm{CuZn}$, and CeAg, Acta Mater. 57 (2009) 213-223. doi:10.1016/j.actamat.2008.08.066.

[23] J. Hu, A.C.F. Cocks, A multi-scale self-consistent model describing the lattice deformation in austenitic stainless steels, Int. J. Solids Struct. 78-79 (2016) 21-37. doi:10.1016/j.ijsolstr.2015.09.021.

[24] O. Muránsky, D.G. Carr, P. Šittner, E.C. Oliver, In situ neutron diffraction investigation of deformation twinning and pseudoelastic-like behaviour of extruded 
AZ31 magnesium alloy, Int. J. Plast. 25 (2009) 1107-1127. doi:10.1016/j.ijplas.2008.08.002.

[25] W. Woo, E.-W. Huang, J.-W. Yeh, H. Choo, C. Lee, S.-Y. Tu, In-situ neutron diffraction studies on high-temperature deformation behavior in a CoCrFeMnNi high entropy alloy, Intermetallics. 62 (2015) 1-6. doi:10.1016/j.intermet.2015.02.020.

[26] Y. Wu, W.H. Liu, X.L. Wang, D. Ma, A.D. Stoica, T.G. Nieh, et al., In-situ neutron diffraction study of deformation behavior of a multi-component high-entropy alloy, Appl. Phys. Lett. 104 (2014) 51910. doi:10.1063/1.4863748.

[27] J.R. Santisteban, M.R. Daymond, J.A. James, L. Edwards, ENGIN-X: a thirdgeneration neutron strain scanner, J. Appl. Crystallogr. 39 (2006) 812-825. doi:10.1107/S0021889806042245.

[28] B.H. Toby, EXPGUI, a graphical user interface for GSAS, J. Appl. Crystallogr. 34 (2001) 210-213. doi:10.1107/S0021889801002242.

[29] W.H. Liu, Z.P. Lu, J.Y. He, J.H. Luan, Z.J. Wang, B. Liu, et al., Ductile CoCrFeNiMox high entropy alloys strengthened by hard intermetallic phases, Acta Mater. 116 (2016) 332-342. doi:10.1016/j.actamat.2016.06.063.

[30] P. Ludwik, Elemente der Technologischen Mechanik, Springer Berlin Heidelberg, 1909.

[31] P. Antoine, S. Vandeputte, J.B. Vogt, Empirical model predicting the value of the strain-hardening exponent of a Ti-IF steel grade, Mater. Sci. Eng. A. 433 (2006) 5563. doi:10.1016/j.msea.2006.06.030.

[32] Z. Wu, H. Bei, G.M. Pharr, E.P. George, Temperature dependence of the mechanical properties of equiatomic solid solution alloys with face-centered cubic crystal structures, Acta Mater. 81 (2014) 428-441. doi:10.1016/j.actamat.2014.08.026.

[33] J.S. Jeong, W. Woo, K.H. Oh, S.K. Kwon, Y.M. Koo, In situ neutron diffraction study 
of the microstructure and tensile deformation behavior in Al-added high manganese austenitic steels, Acta Mater. 60 (2012) 2290-2299.

507 doi:10.1016/j.actamat.2011.12.043.

508

509

510

511

512

513

514

515

516

517

518

519

520

521

522

523

524

525

526

527

528

529

[34] J.S. Jeong, Y.M. Koo, I.K. Jeong, S.K. Kim, S.K. Kwon, Micro-structural study of high-Mn TWIP steels using diffraction profile analysis, Mater. Sci. Eng. A. 530 (2011) 128-134. doi:10.1016/j.msea.2011.09.060.

[35] K. Yan, K.-D. Liss, I.B. Timokhina, E. V. Pereloma, In Situ Synchrotron X-ray Diffraction Studies of the Effect of Microstructure on Tensile Behavior and Retained Austenite Stability of Thermo-mechanically Processed Transformation Induced Plasticity Steel, Mater. Sci. Eng. A. 662 (2016) 185-197. doi:10.1016/j.msea.2016.03.048.

[36] A.A. Saleh, E. V. Pereloma, B. Clausen, D.W. Brown, C.N. Tomé, A.A. Gazder, Selfconsistent modelling of lattice strains during the in-situ tensile loading of twinning induced plasticity steel, Mater. Sci. Eng. A. 589 (2014) 66-75. doi:10.1016/j.msea.2013.09.073.

[37] R.P. Reed, R.E. Schramm, Relationship between stacking-fault energy and x-ray measurements of stacking-fault probability and microstrain, J. Appl. Phys. 45 (1974) 4705-4711. doi:10.1063/1.1663122.

[38] F. Tian, L.K. Varga, N. Chen, L. Delczeg, L. Vitos, Ab initio investigation of highentropy alloys of 3d elements, Phys. Rev. B - Condens. Matter Mater. Phys. 87 (2013) 1-8. doi:10.1103/PhysRevB.87.075144.

[39] S. Harjo, Y. Tomota, P. Lukas, D. Neov, M. Vrana, P. Mikula, et al., In situ neutron diffraction study of $\alpha-\gamma \mathrm{Fe}-\mathrm{Cr}$ - Ni alloys under tensile deformation, Acta Mater. 49 (2001) 2471-2479.

[40] A.J. Zaddach, C. Niu, C.C. Koch, D.L. Irving, Mechanical Properties and Stacking 

doi:10.1007/s11837-013-0771-4.

[41] Y. Kim, Y.M. Kim, J.-Y. Koh, T.-H. Lee, W.C. Woo, H.N. Han, Evaluation of single crystal elastic constants and stacking fault energy in high-nitrogen duplex stainless steel by in-situ neutron diffraction, Scr. Mater. 119 (2016) 1-4. doi:10.1016/j.scriptamat.2016.03.013.

[42] T.H. Lee, C.S. Oh, S.J. Kim, S. Takaki, Deformation twinning in high-nitrogen austenitic stainless steel, Acta Mater. 55 (2007) 3649-3662. doi:10.1016/j.actamat.2007.02.023.

[43] Y.F. Shen, Y.D. Wang, X.P. Liu, X. Sun, R. Lin Peng, S.Y. Zhang, et al., Deformation mechanisms of a 20Mn TWIP steel investigated by in situ neutron diffraction and TEM, Acta Mater. 61 (2013) 6093-6106. doi:10.1016/j.actamat.2013.06.051.

D.W. Brown, M.A.M. Bourke, P.S. Dunn, R.D. Field, M.G. Stout, D.J. Thoma, Uniaxial Tensile Deformation of Uranium 6 Wt Pct Niobium : A Neutron Diffraction Study of Deformation Twinning, Metall. Mater. Trans. A. 32A (2001) 2219-2228. doi:10.1007/s11661-001-0197-4.

[45] O. Murannsky, M.R. Barnett, D.G. Carr, S.C. Vogel, E.C. Oliver, Investigation of

[46] S. Mahajan, G.Y. Chin, Formation of deformation twins in fcc crystals, Acta Mater. 21 (1973) 1353-1363.

[47] J.D. Yoo, K.-T. Park, Microband-induced plasticity in a high Mn-Al-C light steel, Mater. Sci. Eng. A. 496 (2008) 417-424. doi:10.1016/j.msea.2008.05.042.

554 [48] T.H. Lee, E. Shin, C.S. Oh, H.Y. Ha, S.J. Kim, Correlation between stacking fault 
energy and deformation microstructure in high-interstitial-alloyed austenitic steels, Acta Mater. 58 (2010) 3173-3186. doi:10.1016/j.actamat.2010.01.056.

[49] O. Bouaziz, S. Allain, C.P. Scott, P. Cugy, D. Barbier, High manganese austenitic twinning induced plasticity steels: A review of the microstructure properties relationships, Curr. Opin. Solid State Mater. Sci. 15 (2011) 141-168. doi:10.1016/j.cossms.2011.04.002.

[50] L. Zhang, R. Song, C. Zhao, F. Yang, Work hardening behavior involving the substructural evolution of an austenite-ferrite Fe-Mn-Al-C steel, Mater. Sci. Eng. A. 640 (2015) 225-234. doi:http://dx.doi.org/10.1016/j.msea.2015.05.108.

[51] D.A. Hughes, Microstructural evolution in a non-cell forming metal: AlMg, Acta Metall. Mater. 41 (1993) 1421-1430. doi:10.1016/0956-7151(93)90251-M.

[52] I. Gutierrez-Urrutia, D. Raabe, Microbanding mechanism in an Fe-Mn-C high-Mn twinning-induced plasticity steel, Scr. Mater. 69 (2013) 53-56. doi:10.1016/j.scriptamat.2013.03.010.

[53] R.J. McCabe, I.J. Beyerlein, J.S. Carpenter, N. a Mara, The critical role of grain orientation and applied stress in nanoscale twinning., Nat. Commun. 5 (2014) 3806. doi:10.1038/ncomms4806.

\section{Figures}

Fig. 1. (a) EBSD of the as-extruded tHEA-Mo alloy; (b) back scattering SEM image of the as-annealed tHEA-Mo alloy (Inset, mapping of Mo distribution).

Fig. 2. Schematic illustration of in situ neutron diffraction measurement and the tensile specimen dimensions $(\mathrm{mm})$.

Fig. 3. The stress-strain curve of tHEA-Mo $\mathrm{Mo}_{0.2}$ alloy in (a) as-extruded and (b) annealed state Fig. 4. Diffraction patterns at stress levels of 0, 418 and $755 \mathrm{MPa}$ of the as-extruded tHEAMo alloy: (a) axial data; (b) radial data. 
580

581

582

583

584

585

586

587

588

589

590

591

592

Fig. 5. (a, b) Lattice strain in the axial direction; (c, d) axial lattice strain evolution of the (111) first order and (222) second order reflections together with the stacking fault probability as a function of true strain; $(e, f)$ normalized intensity as a function of true stress. Note that (a, c and e) are as-extruded alloy, (b, d and f) are annealed.

Fig.6. TEM images of the strained to failure tHEA-Mo alloy at the as-extruded condition: (a) bright field image showing nano-twins; (b) diffraction pattern of the area in (a); (c) BF showing nano-twin intersections; (d) bright field image showing microbands.

Fig.7. TEM images of the strained to failure tHEA-Mo alloy at the as-annealed condition: (a) and (b) bright field TEM; (c) STEM-DF image of intermetallic particles; (d) EDS mapping of the intermetallic particles within the white square box in (e).

Fig.8. (a, b), The longitudinal cross-section; (c, d): the fractograph: (a, c) as-extruded, (b, d) annealed. Inset in c: TEM image of an intermetallic particle. 

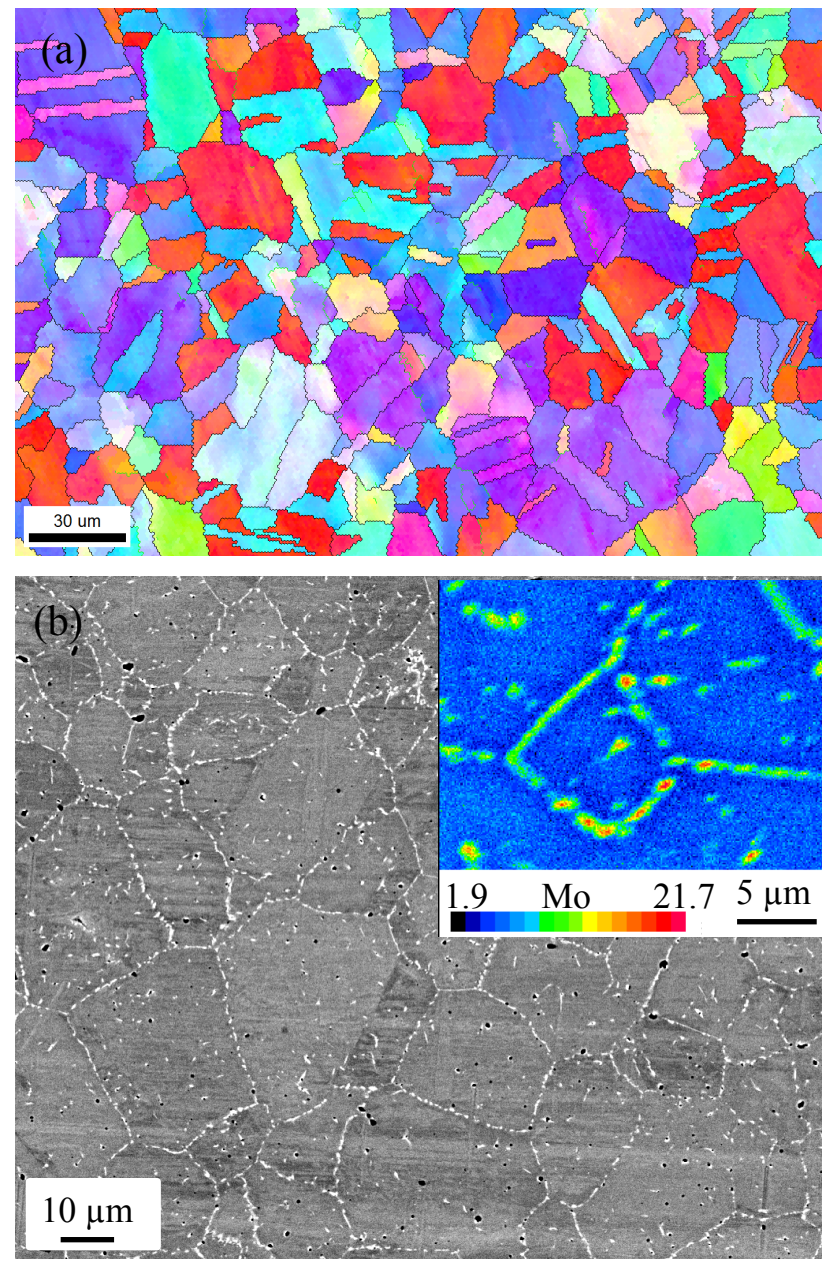

Fig. 1. (a) EBSD of the as-extruded tHEA-Mo alloy; (b) back scattering SEM image of the as-annealed tHEA-Mo alloy (Inset, EPMA mapping of Mo distribution). 

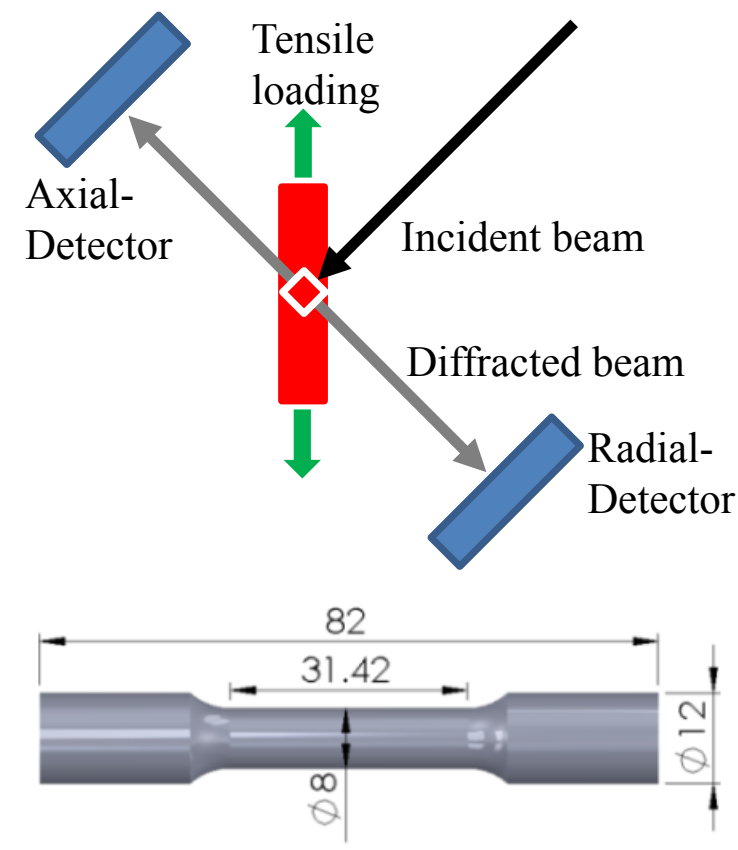

Fig. 2. Schematic illustration of in situ neutron diffraction measurement and the tensile specimen dimensions ( $\mathrm{mm}$ ). 

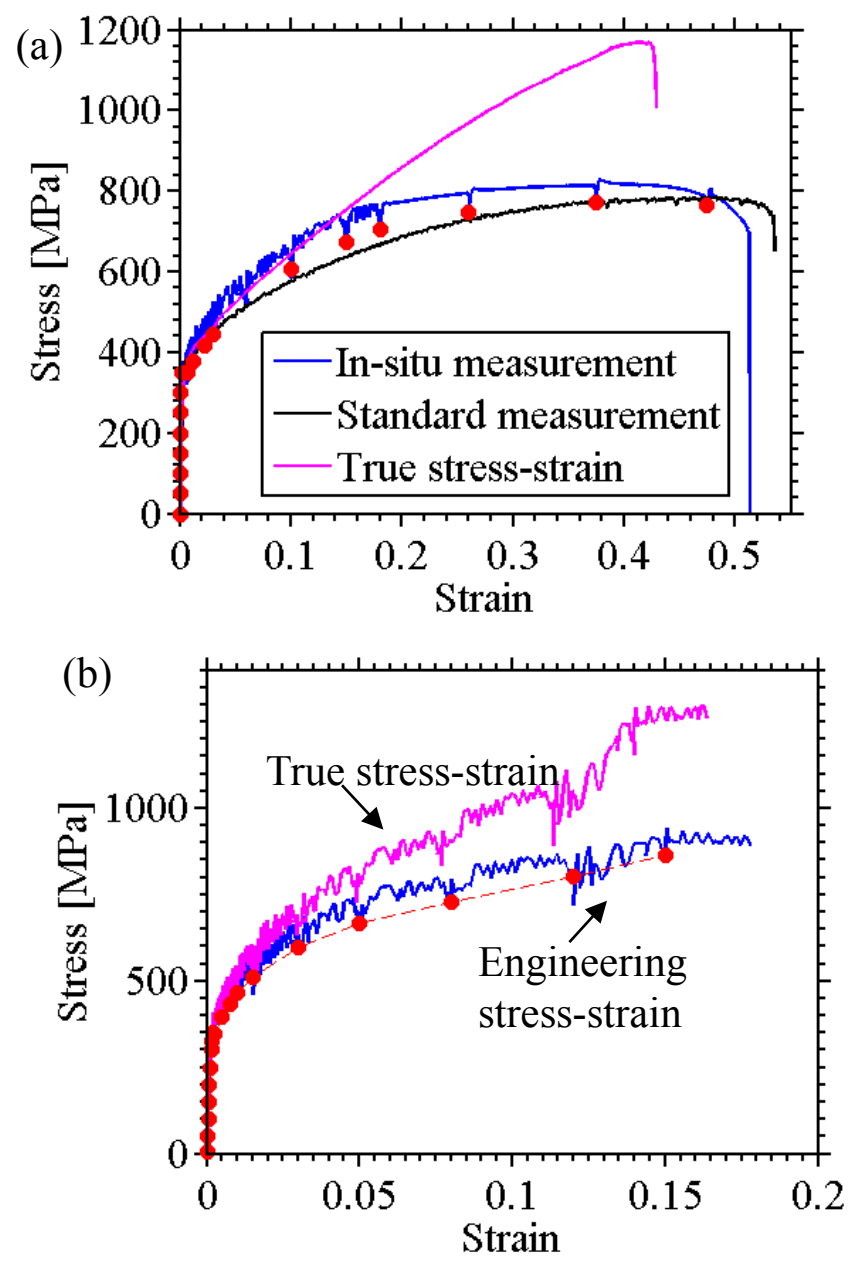

Fig. 3. The stress-strain curve of tHEA- $\mathrm{Mo}_{0.2}$ alloy in (a) as-extruded and (b) annealed state. 

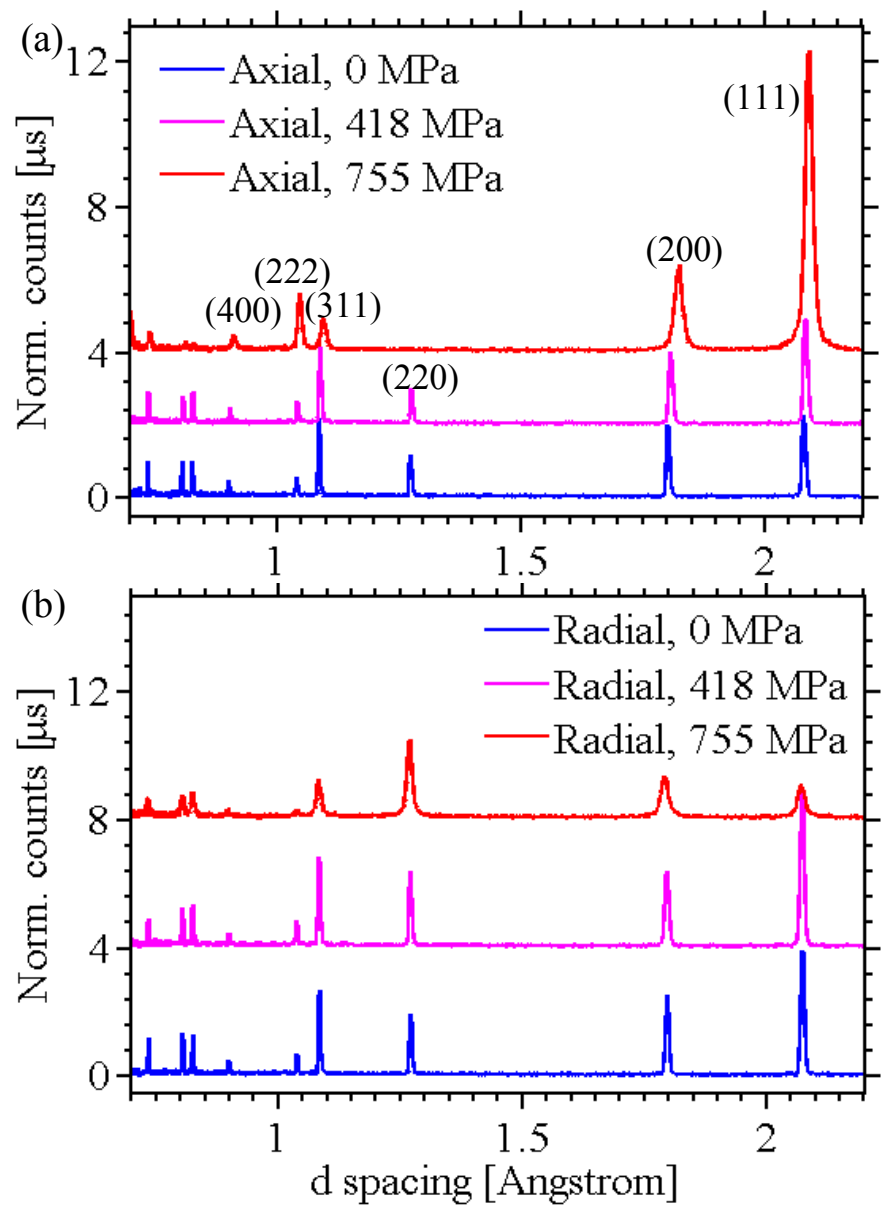

Fig. 4. Diffraction patterns at stress levels of 0,418 and $755 \mathrm{MPa}$ of the as-extruded tHEA-Mo alloy: (a) axial detector data; (b) radial detector data. 
(a)

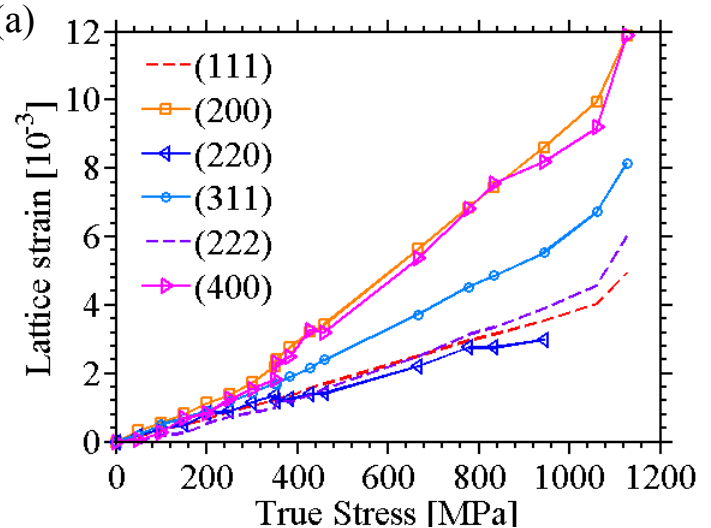

(c)
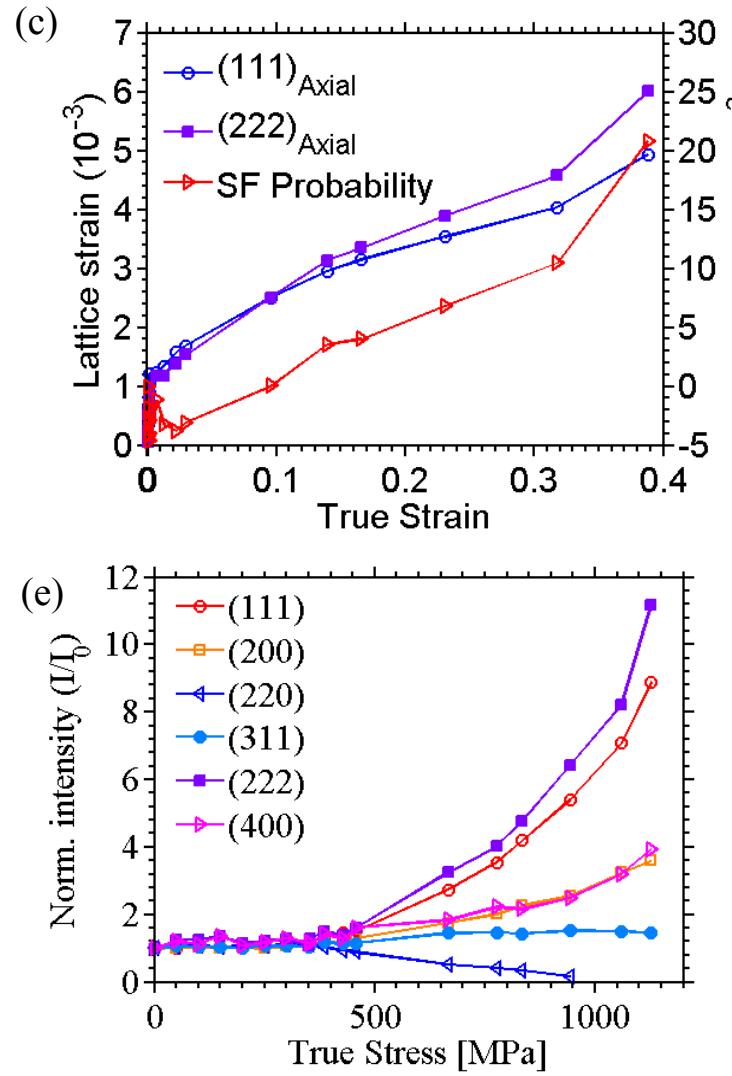

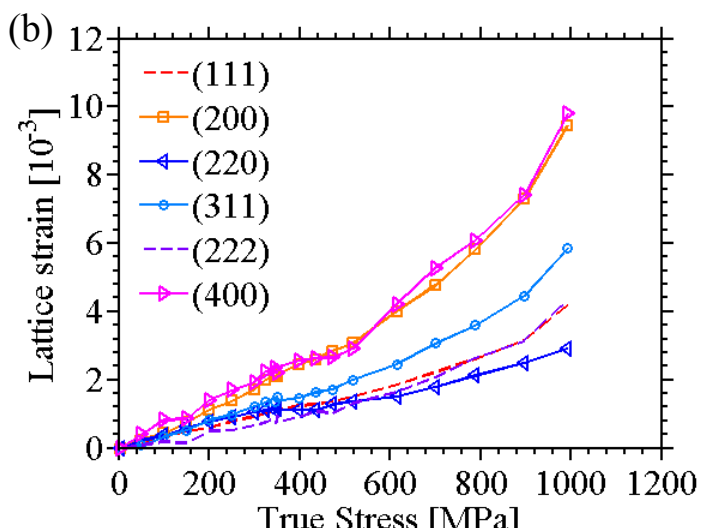

(d)
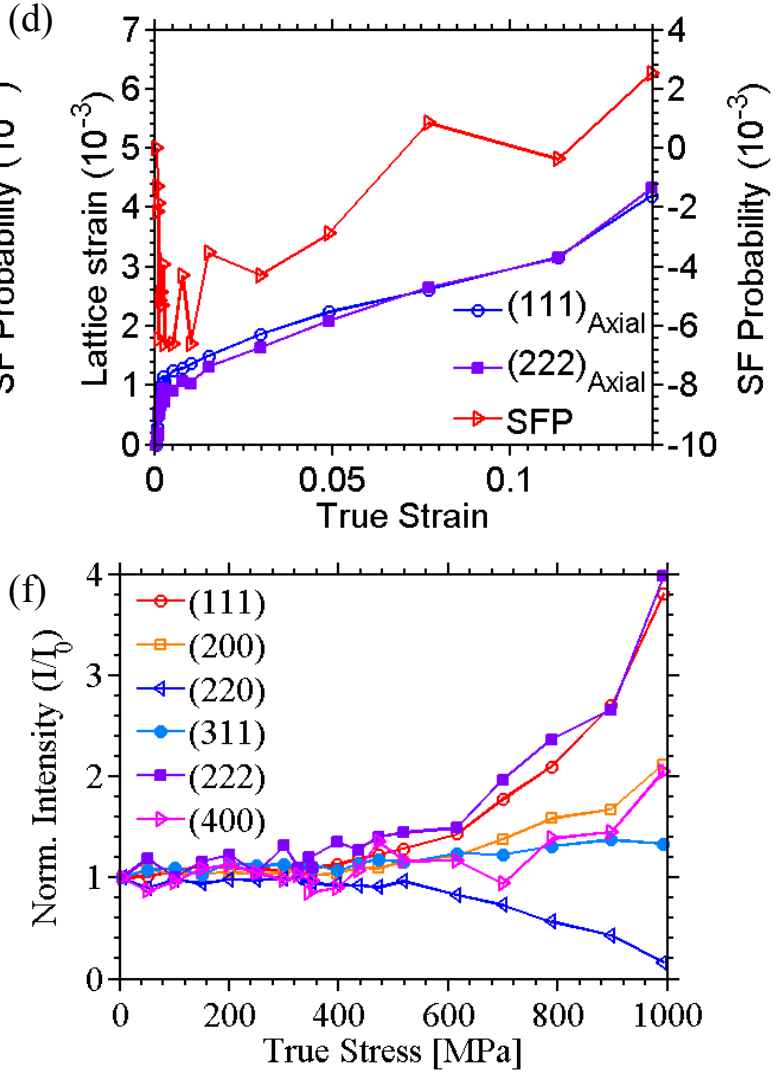

Fig. 5. (a, b) Lattice strain in the axial direction; (c, d) axial lattice strain evolution of the (111) first order and (222) second order reflections together with the stacking fault probability as a function of true strain; $(\mathrm{e}, \mathrm{f})$ normalized intensity as a function of true stress. Note that (a, c and e) are as-extruded alloy, (b, d and f) are annealed alloy. 

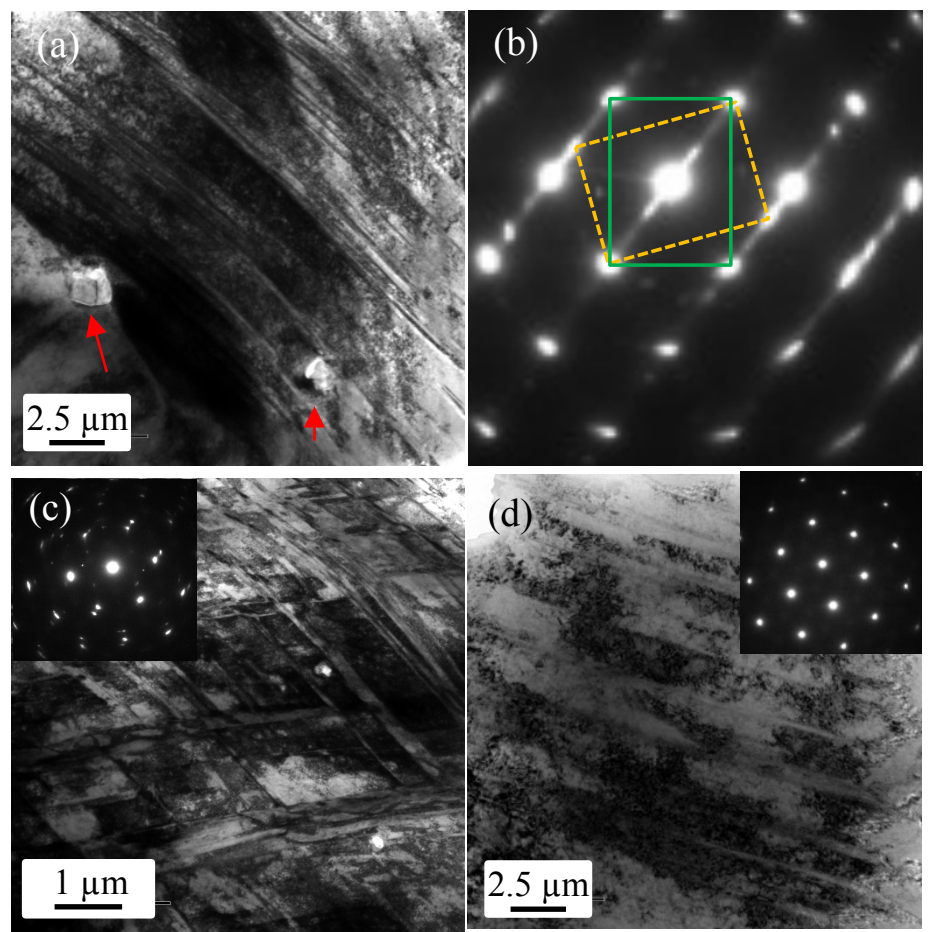

Fig.6. TEM images of the strained to failure tHEA-Mo alloy at the as-extruded condition: (a) bright field image showing nano-twins; (b) diffraction pattern of the area in (a); (c) BF showing nano-twin intersections; (d) bright field image showing microbands. 

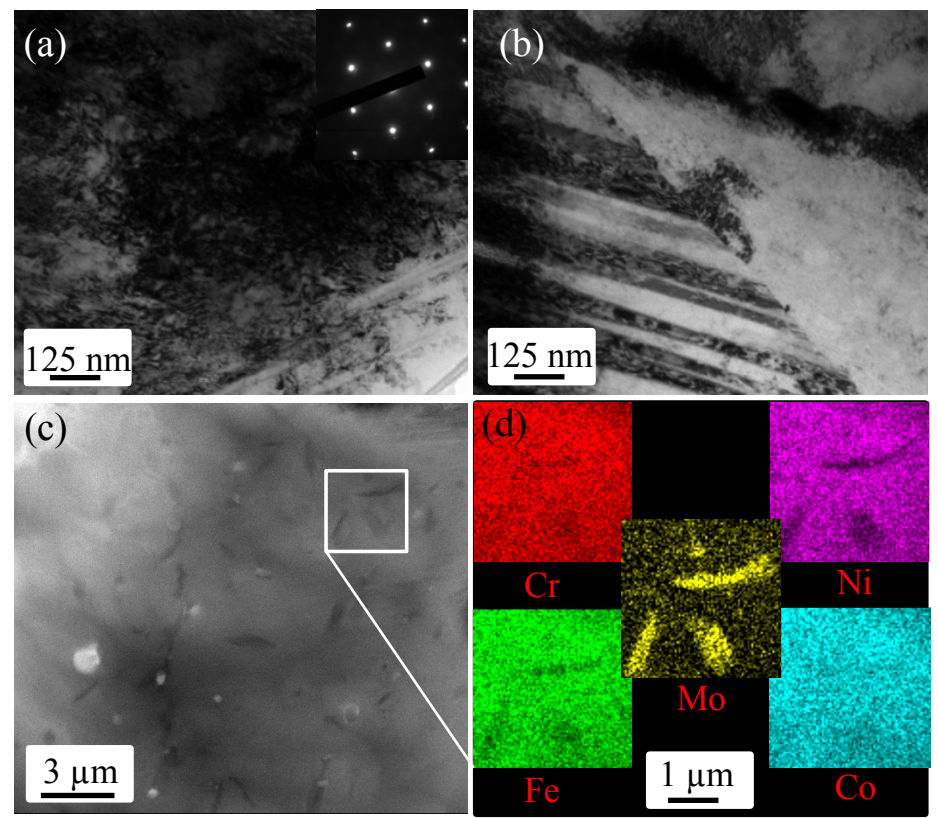

Fig. 7. TEM images of the strained to failure tHEA-Mo alloy at the as-annealed condition: (a) and (b) bright field TEM; (c) STEM-DF image of intermetallic particles; (d) EDS mapping of the intermetallic particles within the white square box in (e). 


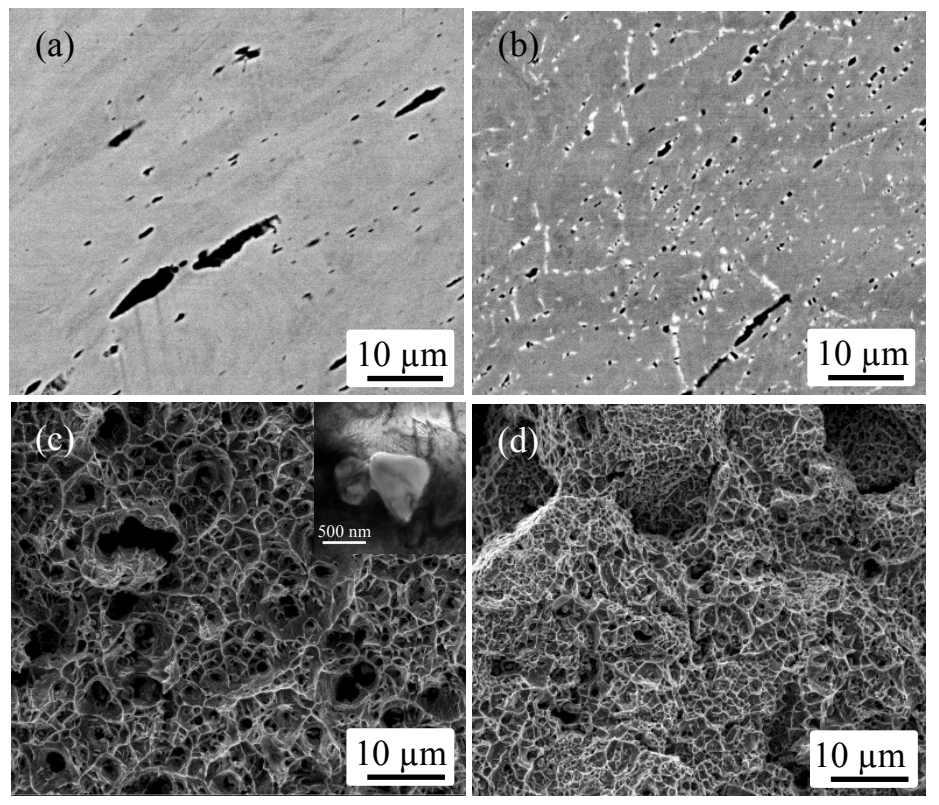

Fig.8. (a, b), the longitudinal cross-section; (c, d): the fractograph of the fractured samples: $(a, c)$ asextruded, $(b, d)$ annealed. Inset in c: TEM image of an intermetallic particle 